CLINICAL STUDY

\title{
Low serum 25-hydroxyvitamin D levels are associated with increased all-cause mortality risk in a general population: the Tromso study
}

\author{
Moira Strand Hutchinson ${ }^{1}$, Guri Grimnes ${ }^{2}$, Ragnar Martin Joakimsen ${ }^{1,2}$, Yngve Figenschau ${ }^{3,4}$ and Rolf Jorde ${ }^{1,2}$ \\ ${ }^{1}$ Department of Clinical Medicine, University of Tromsø, Tromsø, Norway, ${ }^{2}$ Medical Clinic and ${ }^{3}$ Department of Medical Biochemistry, \\ University Hospital of North Norway, Tromsø, Norway and ${ }^{4}$ Department of Medical Biology, University of Tromsø, Tromsø, Norway \\ (Correspondence should be addressed to M S Hutchinson who is now at Medical Department, University Hospital of North Norway, PO Box 101, 9038 \\ Tromsø, Norway; Email: moira-ylva.hutchinson@uit.no)
}

\begin{abstract}
Objective: Ecologic and observational studies have suggested an association between serum 25-hydroxyvitamin D (25(OH)D) levels and cardiovascular disease (CVD) risk factors, CVD mortality, and cancer mortality. Based on this, low serum 25(OH)D levels should be associated with higher all-cause mortality in a general population. This hypothesis was tested in the present study.

Design: The Tromsø study is a longitudinal population-based multipurpose study initiated in 1974 with focus on lifestyle-related diseases. Our data are based on the fourth Tromsø study carried out in 1994-1995.

Methods: Information about death and cause of death was registered by obtaining information from the National Directory of Residents and the Death Cause Registry. Serum 25(OH)D was measured in 7161 participants in the fourth Tromsø study. Results are presented for smokers $(n=2410)$ and non-smokers $(n=4751)$ separately as our immunoassay seems to overestimate $25(\mathrm{OH}) \mathrm{D}$ levels for smokers.

Results: During a mean 11.7 years of follow-up, 1359 (19.0\%) participants died. In multivariate regression models, there was a significantly increased risk of all-cause mortality (hazard ratio (HR) 1.32, confidence interval (CI) 1.07-1.62) among non-smoking participants in the lowest 25(OH)D quartile when compared with participants in the highest quartile. Equivalent results for smokers were not significant (HR 1.06, CI 0.83-1.35).

Conclusions: Low serum 25(OH)D levels were associated with increased all-cause mortality for non-smokers, but the results did not reach statistical significance for smokers. However, low 25(OH)D levels are known to be associated with impaired general health, and randomized controlled studies are needed to address the question of causality.
\end{abstract}

European Journal of Endocrinology $162935-942$

\section{Introduction}

Vitamin D deficiency is prevalent in populations globally, and there is accumulating evidence of a possible association with several common diseases (1). Serum 25-hydroxyvitamin D (25(OH)D) levels have been proposed to influence risk of cancer, autoimmune diseases, infectious diseases, and cardiovascular disease (CVD), as well as the known effect on bone health (2). Supporting this hypothesis is the broad tissue distribution of the $1 \alpha$-hydroxylase enzyme and the vitamin $\mathrm{D}$ receptor (VDR) (2).

There is no consensus as to what is the optimal serum concentration of $25(\mathrm{OH}) \mathrm{D}$, but a serum level of $90-100 \mathrm{nmol} / \mathrm{l}$ has been suggested as the most advantageous serum concentration for all endpoints in a recent review (3). Vitamin D levels below $50 \mathrm{nmol} / \mathrm{l}$ are associated with an increase in serum parathyroid hormone (PTH) levels (4), and a decrease in physical performance among older persons (5). Very high levels of serum $25(\mathrm{OH}) \mathrm{D}$ also seem to be disadvantageous. Data from the NHANES III showed a lower risk of mortality at levels of $75-125 \mathrm{nmol} / \mathrm{l}$, but a higher risk of mortality among women at levels $>125 \mathrm{nmol} / \mathrm{l}$ (6).

Ecologic studies $(7,8)$, observational data $(6,9-15)$, and clinical studies (16) have suggested a possible association between serum 25(OH)D levels and mortality, but findings have not been conclusive. A meta-analysis of randomized controlled trials addressing the association between vitamin D supplementation and total mortality concluded that intake of ordinary doses of vitamin D supplements was associated 
with decreases in mortality rates (16). Vitamin D regimens used in these trials ranged from 300 to $833 \mathrm{IU} /$ day, and no toxic effects were described (16).

Accordingly, there are strong indications of an association between vitamin $\mathrm{D}$ level and risk of mortality. In the present study, we were able to test this hypothesis in a general population based on the measurement of $25(\mathrm{OH}) \mathrm{D}$ in serum samples from the fourth Tromsø study (1994-1995) and information about death and cause of death from national registers.

\section{Materials and methods}

\section{Study population}

The Tromsø study is a longitudinal population-based multipurpose study initiated in 1974 with focus on lifestyle-related diseases (17). The fourth Tromsø study was conducted in two phases in 1994-1995. All individuals aged 25 years or older living in the city of Tromsø were invited to participate in the first phase of the study, resulting in 27158 participants and an attendance rate of $77 \%$. Men aged 55-74 years, women aged 50-74 years, and a random sample of $5-10 \%$ of the remaining age groups between 25 and 84 years were preselected for the second phase of the survey, and $78 \%$ of the 10213 preselected individuals attended (18). The study was conducted by the University of Tromsø in cooperation with the National Health Screening Service. The study was recommended by the Regional Committee for Medical and Health Research Ethics, and was approved by the Norwegian Data Inspectorate. Each participant gave written informed consent prior to the examinations. Serum $25(\mathrm{OH}) \mathrm{D}$ was measured in 7161 of 27159 participants, and the results are presented for non-smokers $(n=4751)$ and smokers $(n=2410)$ separately.

\section{Study variables}

Study variables were obtained by questionnaires, physical examination, and laboratory tests collected at baseline in the Tromsø study, and were recorded in a database for later use. Information about death and cause of death was registered until 31 December 2007 by obtaining information from the National Directory of Residents and the Death Cause Registry. Cause of death was given in International Classification of Diseases (ICD) 9/10 code for CVD death, and in ICD 7 code for cancer death. CVD death was defined as death with diagnosis of ischemic heart disease (ICD 10: I20-I25), cerebral vascular disease (ICD 10: I60-I69), or other diseases of the circulatory system (ICD 10: IO0-I20, I27-I52, and I70-I79). Diagnosis of CVD death was confirmed in hospital records. This was not done for cancer deaths as these were verified through the National Cancer Registry.
Information about smoking status, physical activity, and diabetes was obtained from self-administered questionnaires.

Physical activity score (PAS) as a continuous variable was estimated by adding hours of hard and light physical activity per week, weighting hours of hard physical activity double. Diabetes status was decided from the questionnaire question 'Do you have, or have you had diabetes?'. Participants who answered in affirmative to one of the questions 'Do you have or have you had a cerebral stroke/brain haemorrhage?' and 'Do you have or have you had a heart attack?' were registered with prior CVD. Participants with a cancer diagnosis before the date of inclusion were registered with prior cancer.

Blood pressure was recorded with an automatic device (Dinamap Vital Signs Monitor 1846, Critikon Inc., Tampa, FL, USA) by trained personnel. Participants rested for $2 \mathrm{~min}$ in a sitting position before three readings were done on the upper right arm, separated by 2-min intervals. The average of the two last readings was used in the analysis. Height and weight were measured wearing light clothing and no shoes. Body mass index (BMI) was calculated from height and weight by the formula weight $(\mathrm{kg}) /$ height squared $\left(\mathrm{m}^{2}\right)$. Hypertension was defined as systolic blood pressure of $140 \mathrm{mmHg}$ or higher and/or diastolic blood pressure of $90 \mathrm{mmHg}$ or higher and/or use of antihypertensive medication.

Non-fasting blood samples taken at different hours of the day were collected from an antecubital vein; serum was prepared by centrifugation after $1 \mathrm{~h}$ of respite at room temperature, and was analyzed at the Department of Medical Biochemistry at the University Hospital of North Norway. All analyses were approved by the Norwegian Accreditation Authority. Serum calcium (reference range $2.20-2.60 \mathrm{mmol} / \mathrm{l}$ at the time of the study) was analyzed within a week of sampling using an automated analyzer (Modular P, Roche Diagnostics) with reagents from Boehringer Mannheim. Serum PTH was analyzed in 2001 in a subgroup of 3570 participants using an automated clinical chemical analyzer (Immulite 2000, Diagnostic Products Corporation, Los Angeles, CA, USA), with a reference range of 1.1-6.8 pmol/l for those who were 50 years and younger, and $1.1-7.5 \mathrm{pmol} / \mathrm{l}$ for those who were older than 50 years. Serum creatinine was analyzed in 1994-1995 by a modified Jaffe reaction (Roche Hitachi 911). Reference range was 55-100 $\mu \mathrm{mol} / \mathrm{l}$ for women and $70-120 \mu \mathrm{mol} / \mathrm{l}$ for men. Serum total cholesterol (reference range 18-29 years, 2.9-6.1 mmol/l; 30-49 years, 3.3-6.9 mmol/l; $>49$ years, $3.9-7.8 \mathrm{mmol} / \mathrm{l})$ and serum triglycerides (reference range $0.20-1.80 \mathrm{mmol} / \mathrm{l}$ ) were analyzed by enzymatic colorimetric methods and commercially available kits (CHOD-PAP for cholesterol and GPO-PAP for triglycerides: Boehringer Mannheim). Serum high-density lipoprotein (HDL)cholesterol (reference range women, 1.0-2.7 mmol/l; 
men, 0.8-2.1 mmol/l) was measured in 1994-1995 by an enzymatic method using an automated analyzer (Modular P, Roche Diagnostics) after precipitation of lower density lipoproteins with heparin and manganese chloride.

For analysis of $25(\mathrm{OH}) \mathrm{D}$, sera from the second phase of the study were stored at $-70{ }^{\circ} \mathrm{C}$. After a median storage time of 13 years, sera were thawed in March 2008 and analyzed for $25(\mathrm{OH}) \mathrm{D}_{3}$, which was determined by immunometry (ECLIA) using an automated clinical chemistry analyzer (Modular E170, Roche Diagnostics). According to the manufacturer, the assay has, for total analytical precision, a coefficient of variation $\leq 7.8 \%$ as judged in any of three different concentrations $(48.6,73.8$, and $177.0 \mathrm{nmol} / \mathrm{l})$. The cross-reactivity with $25(\mathrm{OH}) \mathrm{D}_{2}$ was $<10 \%$, and the analytical sensitivity was $10 \mathrm{nmol} / \mathrm{l}$. Five subjects had $25(\mathrm{OH}) \mathrm{D}$ below the detection limit, and their values were set to $5 \mathrm{nmol} / \mathrm{l}$. At present, the laboratory has no reference values for $25(\mathrm{OH}) \mathrm{D}_{3}$, but the manufacturer provides a population-based reference range of 27.7-107.0 nmol/l for adults as a guideline. With this method, we have found smokers to have 15-20\% higher serum 25(OH)D levels than non-smokers. We have not found this difference when measuring serum $25(\mathrm{OH}) \mathrm{D}$ with other immunological or LC-MS-MS methods (data not shown). For this discrepancy, we have no explanation presently. We have chosen not to adjust for smoking status, as a possible dose-response effect of smoking would make correct adjustment in multivariate regression models difficult. We have therefore presented results for non-smokers and smokers separately.

\section{Statistical analyses}

The distributions of dependent variables were considered normal when evaluated by visual inspection of histograms and $\mathrm{Q}-\mathrm{Q}$ plots, skewness, and kurtosis. The population was divided into intra-monthly vitamin D quartiles by calculating $25(\mathrm{OH}) \mathrm{D}$ quartiles within each month of blood sampling separately. Differences between means of continuous variables were evaluated using linear regression with $P$ for trend. Differences between categorical data were evaluated using logistic regression.

To evaluate differences in all-cause, CVD and cancer mortality risk, survival analysis was performed with multivariate Cox proportional hazards regression models, using the highest $25(\mathrm{OH}) \mathrm{D}$ quartile as a reference to the lower quartiles. Kaplan-Meier curves and log rank tests were also performed.

Variables directly or indirectly correlated with vitamin D metabolism and cardiovascular risk factors were included in the final model. Inclusion was based on both a priori determination of known confounders and/or backward and forward stepwise omnibus tests of model coefficients. The following covariates were



www.eje-online.org 
Table 2 Number of deaths and mortality hazard ratios with $95 \%$ confidence intervals for non-smokers according to intra-monthly $25(\mathrm{OH}) \mathrm{D}$ quartiles.

\begin{tabular}{|c|c|c|c|c|}
\hline & \multicolumn{4}{|c|}{ Serum 25(OH)D quartile non-smokers } \\
\hline & 1 & 2 & 3 & 4 \\
\hline Study participants at risk, $n$ & 1184 & 1187 & 1192 & 1188 \\
\hline All-cause deaths, $n(\%)$ & $247(20.9)$ & $198(16.7)$ & $190(15.9)$ & $163(13.7)$ \\
\hline CVD deaths, $n(\%)$ & $106(9.0)$ & $81(6.8)$ & $62(5.2)$ & $76(6.4)$ \\
\hline Cancer deaths, $n(\%)$ & $72(6.1)$ & $69(5.8)$ & $74(6.2)$ & $58(4.9)$ \\
\hline \multicolumn{5}{|l|}{ All-cause mortality } \\
\hline Unadjusted & $1.58(1.30-1.93)$ & $1.24(1.01-1.53)$ & $1.17(0.95-1.45)$ & 1 (ref) \\
\hline Limited $^{\mathrm{a}}$ & $1.32(1.08-1.61)$ & $1.06(0.86-1.30)$ & $1.05(0.86-1.30)$ & 1 (ref) \\
\hline Extended $^{\mathrm{b}}$ & $1.23(1.00-1.51)$ & $1.02(0.83-1.26)$ & $1.04(0.84-1.28)$ & 1 (ref) \\
\hline Full ${ }^{\mathrm{C}}$ & $1.32(1.07-1.62)$ & $1.06(0.86-1.31)$ & $1.09(0.88-1.34)$ & 1 (ref) \\
\hline \multicolumn{5}{|l|}{ CVD mortality } \\
\hline Unadjusted & $1.45(1.08-1.95)$ & $1.09(0.80-1.49)$ & $0.82(0.59-1.15)$ & 1 (ref) \\
\hline Limited $^{\mathrm{a}}$ & $1.15(0.85-1.55)$ & $0.89(0.65-1.22)$ & $0.72(0.52-1.01)$ & 1 (ref) \\
\hline Extended $^{\mathrm{b}}$ & $1.03(0.76-1.40)$ & $0.87(0.63-1.19)$ & $0.69(0.49-0.97)$ & 1 (ref) \\
\hline Full ${ }^{\mathrm{C}}$ & $1.08(0.79-1.48)$ & $0.84(0.61-1.15)$ & $0.71(0.51-1.01)$ & 1 (ref) \\
\hline \multicolumn{5}{|l|}{ Cancer mortality } \\
\hline Unadjusted & $1.30(0.92-1.83)$ & $1.22(0.86-1.72)$ & $1.28(0.91-1.81)$ & 1 (ref) \\
\hline Limited $^{\mathrm{a}}$ & $1.14(0.80-1.61)$ & $1.08(0.76-1.53)$ & $1.19(0.85-1.68)$ & 1 (ref) \\
\hline Extended $^{\mathrm{b}}$ & $1.07(0.75-1.53)$ & $1.06(0.74-1.50)$ & $1.18(0.83-1.66)$ & 1 (ref) \\
\hline Full $^{\mathrm{C}}$ & $1.14(0.80-1.63)$ & $1.13(0.80-1.61)$ & $1.23(0.87-1.75)$ & 1 (ref) \\
\hline
\end{tabular}

Multivariate Cox proportional hazards regression models were used to calculate hazard ratios with $95 \%$ confidence intervals. Values are presented as $n$ (percentage of study participants at risk) and as hazard ratio (95\% confidence interval). 25(OH)D, 25-hydroxyvitamin D; CVD, cardiovascular disease; ref, reference.

aLimited model: adjusted for age and gender.

bextended model: as limited model plus adjustment for BMI, physical activity score, and diabetes.

${ }^{\mathrm{c}}$ Full model: as extended model plus adjustment for hypertension, creatinine, prior CVD, and prior cancer.

included in the final model: age, gender, BMI, PAS, hypertension, diabetes, prior cancer, prior CVD, and creatinine. PTH was not included in the primary analysis as PTH was only measured in half of the study population.

The proportional hazards assumption was tested by stratifying the categorical variables and creating log-log graphs. These were all parallel. When examining the partial residuals in scatter plots against survival time, the residuals were found to be evenly distributed.

Confounding was assessed by adding age, gender, hypertension, BMI, PAS, creatinine, diabetes, prior cancer, and prior CVD to the model. Interaction was tested by adding product terms to the full model.

Data are presented as percentage or mean \pm s.D. or hazard ratio (HR) with $95 \%$ confidence interval (CI). All tests were done two-sided, and $P<0.05$ was considered statistically significant. Statistical analyses were performed with SPSS version 17.0 (SPSS Inc., Chicago, IL, USA).

\section{Results}

Mean 25(OH)D level in the total non-smoking population was $52.3 \pm 16.5, \quad 53.5 \pm 16.0$ and 51.5 $\pm 16.8 \mathrm{nmol} / \mathrm{l}$ for men and women respectively $(P<0.001)$. Mean $25(\mathrm{OH}) \mathrm{D}$ level for smokers was $72.0 \pm 20.1,70.5 \pm 19.0$ and $73.0 \pm 20.7 \mathrm{nmol} / \mathrm{l}$ for men and women respectively $(P=0.002)$.
The highest 25(OH)D levels for non-smokers were found in September (mean 61.0 $\pm 17.1 \mathrm{nmol} / \mathrm{l}$ ) and the lowest in March (mean $44.7 \pm 15.5 \mathrm{nmol} / \mathrm{l}$ ). The same pattern was seen for smokers with highest levels in August (mean $79.7 \pm 20.0 \mathrm{nmol} / \mathrm{l}$ ) and lowest levels in March (mean $65.5 \pm 17.6 \mathrm{nmol} / \mathrm{l}$ ).

Mean age in the total population was $58.9 \pm 10.2$. Background characteristics are presented in Table 1. In the non-smoking population, PAS, creatinine, and HDL increased significantly, while age, BMI, total cholesterol, triglycerides, PTH and percentage of women and hypertension decreased significantly across 25(OH)D quartiles. Background characteristics for smokers were similar, and are also presented in Table 1.

Mean follow-up time for non-smokers and smokers was $11.8 \pm 2.6$ and $11.4 \pm 3.0$ years respectively. During this period, 798 non-smokers $(16.8 \%)$ and 561 smokers $(23.3 \%)$ died. Among non-smokers and smokers respectively, $325(40.7 \%)$ and $188(33.5 \%)$ died of CVD (165 and 102 of ischemic heart disease, and 77 and 29 of cerebrovascular disease), and 273 (34.2\%) and $225(40.1 \%)$ died of cancer. The risk of all-cause, CVD, and cancer mortality for individuals in the lower $25(\mathrm{OH}) \mathrm{D}$ quartiles in reference to the highest quartile is shown in unadjusted, limited (adjusted for age and gender), extended (adjusted for age, gender, BMI, diabetes, and PAS), and full models (adjusted for the previously mentioned plus prior CVD, prior cancer, hypertension, and creatinine) for non-smokers in Table 2 and for smokers in Table 3. In the non-smoking 
Table 3 Number of deaths and mortality hazard ratios with 95\% confidence intervals for smokers according to intra-monthly $25(\mathrm{OH}) \mathrm{D}$ quartiles.

\begin{tabular}{|c|c|c|c|c|}
\hline & \multicolumn{4}{|c|}{ Serum 25(OH)D quartile smokers } \\
\hline & 1 & 2 & 3 & 4 \\
\hline Study participants at risk, $n$ & 597 & 606 & 607 & 600 \\
\hline All-cause deaths, $n(\%)$ & $156(26.1)$ & $143(23.6)$ & $138(22.7)$ & $124(20.7)$ \\
\hline CVD deaths, $n(\%)$ & $45(7.5)$ & $57(9.4)$ & $46(7.6)$ & $40(6.7)$ \\
\hline Cancer deaths, $n(\%)$ & $55(9.2)$ & $54(8.9)$ & $60(9.9)$ & $56(9.3)$ \\
\hline \multicolumn{5}{|l|}{ All-cause mortality } \\
\hline Unadjusted & $1.30(1.03-1.65)$ & $1.17(0.92-1.49)$ & $1.09(0.85-1.39)$ & 1 (ref) \\
\hline Limited $^{\mathrm{a}}$ & $1.08(0.85-1.37)$ & $1.01(0.80-1.29)$ & $0.98(0.77-1.25)$ & 1 (ref) \\
\hline Extended $^{\mathrm{b}}$ & $1.05(0.82-1.33)$ & $0.96(0.75-1.23)$ & $0.97(0.76-1.25)$ & 1 (ref) \\
\hline Full ${ }^{\mathrm{C}}$ & $1.06(0.83-1.35)$ & $0.97(0.76-1.25)$ & $1.04(0.81-1.33)$ & 1 (ref) \\
\hline \multicolumn{5}{|l|}{ CVD mortality } \\
\hline Unadjusted & $1.16(0.76-1.78)$ & $1.44(0.96-2.16)$ & $1.12(0.73-1.71)$ & 1 (ref) \\
\hline Limited $^{\mathrm{a}}$ & $0.92(0.60-1.42)$ & $1.23(0.82-1.84)$ & $1.01(0.66-1.54)$ & 1 (ref) \\
\hline Extended $^{\mathrm{b}}$ & $0.90(0.58-1.39)$ & $1.14(0.75-1.73)$ & $0.98(0.64-1.51)$ & 1 (ref) \\
\hline Full ${ }^{\mathrm{C}}$ & $0.93(0.61-1.44)$ & $1.10(0.73-1.67)$ & $1.04(0.67-1.60)$ & 1 (ref) \\
\hline \multicolumn{5}{|l|}{ Cancer mortality } \\
\hline Unadjusted & $1.02(0.70-1.48)$ & $0.98(0.67-1.42)$ & $1.05(0.73-1.51)$ & 1 (ref) \\
\hline Limited $^{\mathrm{a}}$ & $0.88(0.61-1.29)$ & $0.87(0.60-1.27)$ & $0.96(0.66-1.37)$ & 1 (ref) \\
\hline Extended $^{\mathrm{b}}$ & $0.85(0.58-1.25)$ & $0.85(0.58-1.25)$ & $0.96(0.66-1.38)$ & 1 (ref) \\
\hline Full ${ }^{\mathrm{c}}$ & $0.82(0.56-1.21)$ & $0.86(0.59-1.26)$ & $1.02(0.70-1.48)$ & 1 (ref) \\
\hline
\end{tabular}

Multivariate Cox proportional hazards regression models were used to calculate hazard ratios with 95\% confidence intervals. Values are presented as $n$ (percentage of study participants at risk) and as hazard ratio (95\% confidence interval). 25(OH)D, 25-hydroxyvitamin D; CVD, cardiovascular disease; ref, reference.

aLimited model: adjusted for age and gender.

bextended model: as limited model plus adjustment for BMI, physical activity score, and diabetes.

cFull model: as extended model plus adjustment for hypertension, serum creatinine, prior CVD, and prior cancer.

population, risk of all-cause death was significantly increased in the lowest $25(\mathrm{OH}) \mathrm{D}$ quartile. In the full multivariate regression model, individuals with $25(\mathrm{OH}) \mathrm{D}$ in the lowest quartile had a HR of 1.32 (CI 1.07-1.62; Kaplan-Meier curve analysis and log rank test $P<0.001)$ for all-cause death. Regarding CVD and cancer mortality separately, the results were not significant. However, there seemed to be a tendency for higher CVD mortality in the lowest quartile and for cancer mortality in the three lower quartiles when compared with the highest quartile. Results for smokers were not significant, but they showed a tendency for higher all-cause mortality in the lowest quartile.

Interaction was tested between $25(\mathrm{OH}) \mathrm{D}$ quartile and all other components of the Cox regression model in the non-smoking population. To explore whether an effect of $25(\mathrm{OH}) \mathrm{D}$ on all-cause mortality was related to specific subgroups, subgroup analysis was performed in the non-smoking population. Results are presented in Table 4. There were no significant interactions, but mortality risk in the lowest $25(\mathrm{OH}) \mathrm{D}$ quartile was found to be higher among men, and among participants with $\mathrm{BMI}<30$, diabetes, prior CVD, prior cancer, age $<65$ years, and high PAS.

In sensitivity analysis of data from the non-smoking population, adding calcium to the fully adjusted model did not change the all-cause mortality significantly (HR 1.31, CI 1.07-1.62), nor did excluding prior CVD (HR 1.27, CI 1.03-1.56), prior cancer (HR 1.31, 1.06-1.60), PAS (HR 1.37, CI 1.12-1.68), or creatinine
(HR 1.26, CI 1.03-1.55). When including PTH in the fully adjusted model $(n=2190)$, the result for all-cause mortality was similar, but not significant (HR 1.35, CI 0.98-1.84). When excluding participants with creatinine $>120 \mu \mathrm{mol} / \mathrm{l}(n=4679)$, results were unaffected (HR 1.32, CI 1.07-1.63).

\section{Discussion}

In this population-based study, all-cause mortality risk was significantly increased among non-smoking study participants in the lowest vitamin D quartile when compared with the highest quartile. The same tendency was seen for smokers, but these results were not significant. Serum 25(OH)D is the preferred biomarker for an individual's vitamin D status as serum levels are not tightly regulated and increase in proportion to vitamin D intake (19). 25(OH)D is also very stable in stored serum or plasma samples (20). This characteristic makes accurate, long-term epidemiological studies of circulating 25(OH)D possible (20). Measured serum $25(\mathrm{OH}) \mathrm{D}$ is preferable to predicted $25(\mathrm{OH}) \mathrm{D}$ by vitamin D intake, as dietary sources provide only a portion of total vitamin $\mathrm{D}$, with supplements and synthesis of vitamin D in the skin in association with solar u.v.-B radiation providing the balance (21). Because of the known seasonal variation for $25(\mathrm{OH}) \mathrm{D}$ (22), we used intra-monthly vitamin D quartiles in the analyses. Individuals can be assumed to remain in the 
Table 4 Adjusted associations of 25(OH)D and all-cause mortality risk in specific participant subgroups (non-smokers).

\begin{tabular}{|c|c|c|c|}
\hline \multirow[b]{2}{*}{$\begin{array}{l}\text { Subgroup } \\
\text { ( } n \text { at risk/ } n \text { deaths) }\end{array}$} & \multicolumn{3}{|c|}{ Serum $25(\mathrm{OH}) \mathrm{D}$ quartile non-smokers } \\
\hline & 1 & 4 & $\begin{array}{c}P \text { for } \\
\text { interaction }\end{array}$ \\
\hline \multicolumn{4}{|l|}{ Age (years) } \\
\hline$\leq 65(3214 / 272)$ & $1.53(1.09-2.16)$ & 1 (ref) & 0.44 \\
\hline$>65(1537 / 526)$ & $1.26(0.98-1.64)$ & 1 (ref) & \\
\hline \multicolumn{4}{|l|}{ Gender } \\
\hline Female $(2940 / 375)$ & $1.07(0.79-1.45)$ & 1 (ref) & 0.10 \\
\hline Male $(1811 / 423)$ & $1.53(1.15-2.03)$ & 1 (ref) & \\
\hline \multicolumn{4}{|l|}{ PAS (h/week) } \\
\hline$\leq 5 \mathrm{~h} /$ week $(3948 / 696)$ & $1.28(1.03-1.60)$ & 1 (ref) & 0.12 \\
\hline$>5$ h/week (743/94) & $2.21(1.21-4.04)$ & 1 (ref) & \\
\hline \multicolumn{4}{|l|}{ Hypertension } \\
\hline Present $(2863 / 615)$ & $1.33(0.84-2.11)$ & 1 (ref) & 0.53 \\
\hline Absent $(1879 / 178)$ & $1.32(1.05-1.67)$ & 1 (ref) & \\
\hline \multicolumn{4}{|l|}{ Diabetes } \\
\hline Present (159/81) & $1.81(0.87-3.76)$ & 1 (ref) & 0.76 \\
\hline Absent $(4571 / 712)$ & $1.33(1.07-1.65)$ & 1 (ref) & \\
\hline \multicolumn{4}{|l|}{ Prior CVD } \\
\hline Present $(368 / 150)$ & $1.90(1.17-3.08)$ & 1 (ref) & 0.14 \\
\hline Absent $(4363 / 641)$ & $1.20(1.95-1.51)$ & 1 (ref) & \\
\hline \multicolumn{4}{|l|}{ Prior cancer } \\
\hline Present $(266 / 94)$ & $2.34(1.24-4.40)$ & 1 (ref) & 0.09 \\
\hline Absent $(4485 / 704)$ & $1.21(0.97-1.51)$ & 1 (ref) & \\
\hline \multicolumn{4}{|l|}{ BMI $\left(\mathrm{kg} / \mathrm{m}^{2}\right)$} \\
\hline$\leq 30(3936 / 623)$ & $1.35(1.07-1.70)$ & 1 (ref) & 0.86 \\
\hline$>30(803 / 174)$ & $0.95(0.60-1.52)$ & 1 (ref) & \\
\hline
\end{tabular}

Multivariate Cox proportional hazards regression models were used to calculate hazard ratios with $95 \%$ confidence intervals. Values are presented as hazard ratio ( $95 \%$ confidence interval). $P$ values for interactions were calculated by adding product terms to the full Cox regression model. $25(\mathrm{OH})$ D, 25-hydroxyvitamin D; PAS, physical activity score; CVD, cardiovascular disease; BMI, body mass index; ref, reference.

same $25(\mathrm{OH}) \mathrm{D}$ quartile throughout the year as a person's 25(OH)D levels tend to be consistent when measured 12 months apart, although the same person can have significantly higher $25(\mathrm{OH}) \mathrm{D}$ levels during summer than during winter $(23,24)$. However, outdoor exposure time, sun exposure, dietary vitamin D intake/supplements, and skin pigmentation may cause considerable individual variations $(23,24)$. Decreased outdoor exposure time among chronically ill or elderly homebound individuals may especially affect seasonal $25(\mathrm{OH}) \mathrm{D}$ variation, as shown by Melin et al. who found seasonal variation only among elderly individuals with outdoor exposure time $>3 \mathrm{~h} /$ week $(24)$.

Results from other cohort studies indicate an increased risk of mortality in participants with low levels of serum 25(OH)D $(6,10-14)$. Data from NHANES III showed increased all-cause mortality, but not CVD mortality in a general population (6), while increased CVD mortality was found in a Finish population study (14). The same associations were seen among patients referred for coronary angiography (10). Increased risk of all-cause and CVD mortality among elderly with low serum 25(OH)D levels was found both in the Hoorn study (11) and in the InCHIANTI study (12).
The inverse association between all-cause mortality and vitamin $\mathrm{D}$ level could in part be explained by an association between CVD and vitamin D level. Several studies have described an inverse association, in some cases graded, between serum 25(OH)D and CVD (13, 25-27), and CVD risk factors (28). Giovannucci et al. found increased risk of fatal and non-fatal myocardial infarction in men with low levels of $25(\mathrm{OH}) \mathrm{D}$ (13). Low levels of $25(\mathrm{OH}) \mathrm{D}$ and $1,25(\mathrm{OH})_{2} \mathrm{D}$ were shown to be independently predictive of fatal stroke among patients referred to coronary angiography in the LURIC study (29). In the Framingham Offspring study, low serum 25(OH)D levels were associated with higher CVD risk among individuals with hypertension, but not among normotensive individuals (27).

Observational and cross-sectional studies have also indicated an inverse association between serum $25(\mathrm{OH}) \mathrm{D}$ level and incident hypertension $(30,31)$. Furthermore, low serum 25(OH)D levels are associated with elevated PTH levels (32), and excess PTH levels may also contribute to CVD by increasing blood pressure (33) and inducing cardiomyocyte hypertrophy and interstitial fibrosis of the heart $(32,33)$. In the Tromsø study, men with left ventricular hypertrophy had higher PTH levels compared with men without left ventricular hypertrophy (34), and a recent study showed that plasma PTH levels predict cardiovascular mortality even in individuals with PTH within the normal range (35).

Another plausible mechanism for the association between vitamin $\mathrm{D}$ and hypertension is the activation of the renin-angiotensin system (RAS) (32). 1,25(OH) ${ }_{2} \mathrm{D}$ is known to be a negative endocrine regulator of the RAS (36), and experiments on VDR knockout mice suggest that cardiac hypertrophy is a consequence of activation of both the systemic and cardiac RAS (37). In addition, the immune system appears to be involved in the pathogenesis of atherosclerosis (38), and $1,25(\mathrm{OH})_{2} \mathrm{D}$ appears to have immunosuppressive effects with reduction of lymphocyte proliferation and production of cytokines (39).

Although some other studies $(40,41)$ have reported an inverse association between serum 25(OH)D level and cancer mortality, we did not find such an association in our study. Observational studies have shown cancer survival to be better when cancer is diagnosed in summer and autumn months when vitamin D levels are higher $(9,42,43)$, and in one of the few intervention studies published, improving calcium and vitamin D nutritional status reduced allcancer risk among healthy postmenopausal women (40). However, the evidence is not conclusive, as pointed out in a recent review asking for more randomized controlled trials (44).

In subgroup analysis of our data, there was a tendency towards higher mortality risk among men in the lower $25(\mathrm{OH}) \mathrm{D}$ quartile when compared with women. The same trend was found for CVD 
and cancer mortality. The gender difference found in our study has not been described in other studies. On the contrary, results from NHANES III showed the association between $25(\mathrm{OH}) \mathrm{D}$ levels and mortality to be more pronounced among women (6). We have no good explanation for this discrepancy. As most participants were aged up to 74 years, a possible explanation for the gender difference could be that women experience CVD later in life compared with men.

The main limitation of our study is that we cannot draw any conclusions about causality as it is an observational study. Also, as our immunoassay seems to overestimate serum $25(\mathrm{OH}) \mathrm{D}$ in smokers, and bearing in mind the probable dose-response effect of smoking which makes it difficult to adjust for smoking status in the analyses, our results for smokers should be interpreted with care. A further limitation is that low vitamin D status is known to be associated with impaired general health, probably because of less time spent outdoors (45). Serum 25(OH)D level is known to predict decline of physical performance (5) and nursing home admission (46) among older persons. We tried to adjust for this by including PAS, age, BMI, prior CVD, prior cancer, diabetes, and hypertension in the regression models, but it is impossible to fully adjust for impaired general health. Subgroup analysis of our data was ambiguous with regard to this aspect, as higher mortality risk was found in the lowest $25(\mathrm{OH}) \mathrm{D}$ quartile among those with high PAS, BMI $<30 \mathrm{~kg} / \mathrm{m}^{2}$, and age $<65$ years, but also among those with diabetes, prior cancer, and prior CVD. Lastly, data used in our analyses were obtained from a general health survey not specifically designed for the present purpose.

However, the study also has considerable strengths. The Tromsø study has a high attendance rate, and reflects the general population in Tromsø County. We also had a long follow-up time, a relatively old population, and thus a relatively high percentage of death among participants.

In conclusion, survival analyses of data from our prospective, population-based cohort study show that being in the lowest intra-monthly serum 25(OH)D quartile is associated with higher risk of all-cause mortality, but conclusions about causality cannot be drawn. Further observational studies and randomized clinical trials are needed in order to conclude whether serum $25(\mathrm{OH}) \mathrm{D}$ is associated with mortality, and if so, whether vitamin D supplementation could be beneficial in reducing mortality risk.

\section{Declaration of interest}

The authors declare that there is no conflict of interest that could be perceived as prejudicing the impartiality of the research reported.

\section{Funding}

This work was supported by the University of Tromsø, Tromsø, Norway, and the Northern Norway Regional Health Authority.

\section{Acknowledgements}

The superb assistance by Inger Myrnes, Astrid Lindvall, Ole-Martin Sand, and Tom Sollid at the Department of Medical Biochemistry, University Hospital of North Norway, and by Tom Wilsgaard at the Department of Community Medicine, University of Tromsø, is gratefully acknowledged.

\section{References}

1 Holick MF. Vitamin D deficiency. New England Journal of Medicine $2007357266-281$.

2 Maalouf NM. The noncalciotropic actions of vitamin D: recent clinical developments. Current Opinion in Nephrology and Hypertension 200817 408-415.

3 Bischoff-Ferrari HA, Giovannucci E, Willett WC, Dietrich T \& Dawson-Hughes B. Estimation of optimal serum concentrations of 25-hydroxyvitamin D for multiple health outcomes. American Journal of Clinical Nutrition $2006 \mathbf{8 4} 18-28$.

4 Lips P. Vitamin D deficiency and secondary hyperparathyroidism in the elderly: consequences for bone loss and fractures and therapeutic implications. Endocrine Reviews 200122 477-501.

5 Wicherts IS, van Schoor NM, Boeke AJ, Visser M, Deeg DJ, Smit J, Knol DL \& Lips P. Vitamin D status predicts physical performance and its decline in older persons. Journal of Clinical Endocrinology and Metabolism 200792 2058-2065.

6 Melamed ML, Michos ED, Post W \& Astor B. 25-Hydroxyvitamin D levels and the risk of mortality in the general population. Archives of Internal Medicine $2008 \mathbf{1 6 8} 1629-1637$.

7 Grant WB. An estimate of premature cancer mortality in the U.S. due to inadequate doses of solar ultraviolet-B radiation. Cancer $2002941867-1875$.

8 Grant WB \& Garland CF. The association of solar ultraviolet B (UVB) with reducing risk of cancer: multifactorial ecologic analysis of geographic variation in age-adjusted cancer mortality rates. Anticancer Research $2006262687-2699$.

9 Porojnicu AC, Dahlback A \& Moan J. Sun exposure and cancer survival in Norway: changes in the risk of death with season of diagnosis and latitude. Advances in Experimental Medicine and Biology 2008 624 43-54.

10 Dobnig H, Pilz S, Scharnagl H, Renner W, Seelhorst U, Wellnitz B, Kinkeldei J, Boehm BO, Weihrauch G \& Maerz W. Independent association of low serum 25-hydroxyvitamin D and 1,25dihydroxyvitamin D levels with all-cause and cardiovascular mortality. Archives of Internal Medicine 2008168 1340-1349.

11 Pilz S, Dobnig H, Nijpels G, Heine RJ, Stehouwer CD, Snijder MB, van Dam RM \& Dekker JM. Vitamin D and mortality in older men and women. Clinical Endocrinology 200971 666-672.

12 Semba RD, Houston DK, Bandinelli S, Sun K, Cherubini A, Cappola AR, Guralnik JM \& Ferrucci L. Relationship of 25-hydroxyvitamin D with all-cause and cardiovascular disease mortality in older community-dwelling adults. European Journal of Clinical Nutrition 201064 203-209.

13 Giovannucci E, Liu Y, Hollis BW \& Rimm EB. 25-Hydroxyvitamin $\mathrm{D}$ and risk of myocardial infarction in men: a prospective study. Archives of Internal Medicine $2008 \mathbf{1 6 8} 1174-1180$.

14 Kilkkinen A, Knekt P, Aro A, Rissanen H, Marniemi J, Heliovaara M, Impivaara O \& Reunanen A. Vitamin D status and the risk of cardiovascular disease death. American Journal of Epidemiology $20091701032-1039$.

15 Kuroda T, Shiraki M, Tanaka S \& Ohta H. Contributions of 25-hydroxyvitamin D, co-morbidities and bone mass to mortality in Japanese postmenopausal women. Bone 200944 168-172. 
16 Autier P \& Gandini S. Vitamin D supplementation and total mortality: a meta-analysis of randomized controlled trials. Archives of Internal Medicine $2007 \mathbf{1 6 7} 1730-1737$.

17 Thelle DS, Foorde OH, Try K \& Lehmann EH. The Tromso Heart Study. Methods and main results of the cross-sectional study. Acta Medica Scandinavica 1976200 107-118.

18 Jorde R \& Bonaa KH. Calcium from dairy products, vitamin D intake, and blood pressure: the Tromso Study. American Journal of Clinical Nutrition 200071 1530-1535.

19 Holick MF. The cutaneous photosynthesis of previtamin $\mathrm{D}_{3}$ : a unique photoendocrine system. Journal of Investigative Dermatology 198177 51-58.

20 Hollis BW. Measuring 25-hydroxyvitamin D in a clinical environment: challenges and needs. American Journal of Clinical Nutrition $2008 \mathbf{8 8}$ 507S-510S.

21 Grant WB \& Garland CF. A critical review of studies on vitamin D in relation to colorectal cancer. Nutrition and Cancer $2004 \mathbf{4 8}$ 115-123.

22 McLaughlin M, Raggatt PR, Fairney A, Brown DJ, Lester E \& Wills MR. Seasonal variations in serum 25-hydroxycholecalciferol in healthy people. Lancet $19741536-538$.

23 Harris SS \& Dawson-Hughes B. Seasonal changes in plasma 25-hydroxyvitamin D concentrations of young American black and white women. American Journal of Clinical Nutrition 199867 $1232-1236$.

24 Melin A, Wilske J, Ringertz H \& Saaf M. Seasonal variations in serum levels of 25-hydroxyvitamin D and parathyroid hormone but no detectable change in femoral neck bone density in an older population with regular outdoor exposure. Journal of the American Geriatrics Society 200149 1190-1196.

25 Cigolini M, Iagulli MP, Miconi V, Galiotto M, Lombardi S \& Targher G. Serum 25-hydroxyvitamin $\mathrm{D}_{3}$ concentrations and prevalence of cardiovascular disease among type 2 diabetic patients. Diabetes Care $200629722-724$.

26 Kim DH, Sabour S, Sagar UN, Adams S \& Whellan DJ. Prevalence of hypovitaminosis D in cardiovascular diseases (from the National Health and Nutrition Examination Survey 2001 to 2004). American Journal of Cardiology 2008102 1540-1544.

27 Wang TJ, Pencina MJ, Booth SL, Jacques PF, Ingelsson E, Lanier K, Benjamin EJ, D’Agostino RB, Wolf M \& Vasan RS. Vitamin D deficiency and risk of cardiovascular disease. Circulation 2008117 503-511.

28 Martins D, Wolf M, Pan D, Zadshir A, Tareen N, Thadhani R, Felsenfeld A, Levine B, Mehrotra R \& Norris K. Prevalence of cardiovascular risk factors and the serum levels of 25-hydroxyvitamin D in the United States: data from the Third National Health and Nutrition Examination Survey. Archives of Internal Medicine 2007 167 1159-1165.

29 Pilz S, Dobnig H, Fischer JE, Wellnitz B, Seelhorst U, Boehm BO \& Marz W. Low vitamin D levels predict stroke in patients referred to coronary angiography. Stroke 200839 2611-2613.

30 Forman JP, Giovannucci E, Holmes MD, Bischoff-Ferrari HA, Tworoger SS, Willett WC \& Curhan GC. Plasma 25-hydroxyvitamin D levels and risk of incident hypertension. Hypertension 200749 1063-1069.

31 Scragg R, Sowers M \& Bell C. Serum 25-hydroxyvitamin D, ethnicity, and blood pressure in the Third National Health and Nutrition Examination Survey. American Journal of Hypertension 200720 713-719.
32 Zittermann A. Vitamin D and disease prevention with special reference to cardiovascular disease. Progress in Biophysics and Molecular Biology 200692 39-48.

33 Rostand SG \& Drueke TB. Parathyroid hormone, vitamin D, and cardiovascular disease in chronic renal failure. Kidney International 199956 383-392.

34 Saleh FN, Schirmer H, Sundsfjord J \& Jorde R. Parathyroid hormone and left ventricular hypertrophy. European Heart Journal $2003242054-2060$.

35 Hagstrom E, Hellman P, Larsson TE, Ingelsson E, Berglund L, Sundstrom J, Melhus H, Held C, Lind L, Michaelsson K \& Arnlov J. Plasma parathyroid hormone and the risk of cardiovascular mortality in the community. Circulation $20091192765-2771$.

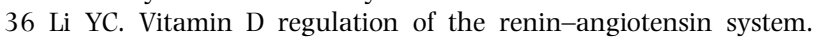
Journal of Cellular Biochemistry $2003 \mathbf{8 8} 327-331$.

37 Xiang W, Kong J, Chen S, Cao LP, Qiao G, Zheng W, Liu W, Li X, Gardner DG \& Li YC. Cardiac hypertrophy in vitamin D receptor knockout mice: role of the systemic and cardiac renin-angiotensin systems. American Journal of Physiology. Endocrinology and Metabolism $2005 \mathbf{2 8 8}$ E125-E132.

38 Hansson GK, Libby P, Schonbeck U \& Yan ZQ. Innate and adaptive immunity in the pathogenesis of atherosclerosis. Circulation Research $200291281-291$.

39 Saggese G, Federico G, Balestri M \& Toniolo A. Calcitriol inhibits the PHA-induced production of IL-2 and IFN-gamma and the proliferation of human peripheral blood leukocytes while enhancing the surface expression of HLA class II molecules. Journal of Endocrinological Investigation 198912 329-335.

40 Lappe JM, Travers-Gustafson D, Davies KM, Recker RR \& Heaney RP. Vitamin D and calcium supplementation reduces cancer risk: results of a randomized trial. American Journal of Clinical Nutrition 200785 1586-1591.

41 Giovannucci E. Vitamin D and cancer incidence in the Harvard cohorts. Annals of Epidemiology 200919 84-88.

42 Robsahm TE, Tretli S, Dahlback A \& Moan J. Vitamin $\mathrm{D}_{3}$ from sunlight may improve the prognosis of breast-, colon- and prostate cancer (Norway). Cancer Causes and Control 200415 149-158.

43 Lim HS, Roychoudhuri R, Peto J, Schwartz G, Baade P \& Moller H. Cancer survival is dependent on season of diagnosis and sunlight exposure. International Journal of Cancer 2006119 1530-1536.

44 Pilz S, Tomaschitz A, Obermayer-Pietsch B, Dobnig H \& Pieber TR. Epidemiology of vitamin D insufficiency and cancer mortality. Anticancer Research 200929 3699-3704.

45 Scragg R \& Camargo CA Jr. Frequency of leisure-time physical activity and serum 25-hydroxyvitamin D levels in the US population: results from the Third National Health and Nutrition Examination Survey. American Journal of Epidemiology 2008168 577-591.

46 Visser M, Deeg DJ, Puts MT, Seidell JC \& Lips P. Low serum concentrations of 25-hydroxyvitamin D in older persons and the risk of nursing home admission. American Journal of Clinical Nutrition $2006 \mathbf{8 4} 616-622$.

Received 2 February 2010

Accepted 22 February 2010 